\title{
Comunidades Gays do ORKUT: encontros, confrontos e (re)construção de identidades ${ }^{1}$
}

\author{
The Gay ORKUT communities: meetings, confrontations and (re)constructions of \\ identities
}

\author{
Andréa Pereira dos Santos ${ }^{2}$ \\ (andreabiblio@gmial.com) \\ Suely Henrique de Aquino Gomes ${ }^{3}$ \\ (suelyhenriquegomes@gmail.com) \\ http://dx.doi.org/10.5216/cei.v14i2.22447
}

\begin{abstract}
Resumo
A atualidade é caracterizada por um mundo simbólico e efêmero, denominado, pela maioria dos teóricos estudados nessa pesquisa, de Pós-Moderno. Busca-se, no presente artigo, refletir sobre a construção das identidades gays, em especial dos frequientadores de comunidades online. Objetiva-se compreender, a partir da análise do discurso, como são (e se são) construídas as identidades gays nas comunidades online hospedadas no ORKUT. Conclui-se que as identidades gays se revelaram diferenciadas, mesmo estando em uma comunidade online teoricamente "homogênea"; além disso, são identidades em constante transformação. No entanto, os discursos dos gays, em muitos casos negativos, são reflexos do sofrimento causado por conta do preconceito ainda muito presente na sociedade atual. Essas identidades, carregadas de sentidos negativos, só se emanciparão quando a sociedade, por meio da educação, desconstruir esse preconceito histórico e arraigado desde a era vitoriana.
\end{abstract}

Palavras-chave: Homoafetividade. Teoria Queer. Ciberespaço. Comunidades online. ORKUT.

\begin{abstract}
The present world is symbolic and ephemeral. It is called Post-Modern by the majority of theoretical studies in this search. This study reflect how these concepts are present in the life of the individual users from on line communities, especially the gay person. The aims goals are identify the constructed identities gays in on line communities hosted on ORKUT by speech analysis. Finally it is concluded that gays were different identities, So, identities are also in constant transformation. However, the gays speeches in many cases negative, are reflections of the suffering caused by the society prejudice present today. The gay prejudice is over only when the society deconstruction this prejudice through education.
\end{abstract}

Keywords: Homoaffectivity. Queer theory. Cyberspace. On line communities. ORKUT.

1 Trata-se dos resultados da pesquisa do Mestrado em Comunicação defendido em 27 de março de 2009. Programa de Pós-Graduação em Comunicação da Faculdade de Comunicação e Biblioteconomia da UFG.

2 Professora Assistente do Curso de Biblioteconomia da Universidade Federal de Goiás e Bibliotecária do Instituto Federal de Educação, Ciência e Tecnologia de Goiás.. Rua 75 n. 46 Centro Goiânia-Go CEP 74055-110.

3 Professora Adjunta do Curso de Biblioteconomia da Universidade Federal de Goiás e docente do Programa de Pesquisa e Pós-Graduação em Comunicação. Campus Samambaia Caixa postal 131 Goiânia Go CEP 74001-970. 


\section{Introdução}

As comunidades do ORKUT são espaços de encontro, confronto e (re)construção de identidades. Surgem a partir da necessidade dos indivíduos em criar espaços de convivência online que possibilitam a identificação de pontos de vista que podem ser coerentes com os outros ou, ao mesmo tempo, provocar confrontos ideológicos na eterna busca do "eu". Tudo isso é possível porque tais comunidades propõem um modelo de comunicação mais amplo, por ser uma rede que potencializa a união e manifestação de uma infinidade de sujeitos.

Essa potencialização da comunicação é uma necessidade constante desde os tempos mais remotos da civilização humana. A humanidade vem atualizando e aprimorando cada vez mais os meios de comunicação. Estas variadas formas comunicativas (por meio de desenho, escrita, gestos entre outros) criam práticas culturais, saberes e ideologias. Por isso, a comunicação, em suas novas formas, constitui-se em estratégia mais intensa de interação entre os indivíduos, permitindo a construção de identidades por meio de enunciados e discursos.

A cibercultura e com ela o ciberespaço tornam possíveis outros modelos de interação social ou redes sociais. Estas são construídas a partir da manifestação de afeto e/ou amizade entre sujeitos que, em alguns casos, podem se conhecer fisicamente e utilizam o ciberespaço para aumentar suas redes de relacionamento, criando, muitas vezes, amizades ou namoros somente no plano online.

Há diversas comunidades hospedadas pelo ORKUT que tratam de diferenciados assuntos propondo além da interação entre as pessoas a construção de debates. Entretanto, existem comunidades que são espaços de fluidez, efêmeras e de tribos que prezam pelo aqui e agora; ignoram a ética comunitária de bem estar e ligações duradouras, em prol de uma ética da estética ${ }^{4}$ (MAFFESOLI, 2006).

Os ambientes online têm atraído a atenção de diversos pesquisadores pelo seu imenso potencial de promover novas formas de convivência e de sociabilidade, acenando para possibilidades, entre outras, de mobilização e libertação de grupos minoritários (ou maioria silenciosas ${ }^{5}$ ), uma vez que, indiscriminadamente, oferece oportunidades para que se possa superar paradoxos e discursos

4 Para Maffesoli (2006) na ética da estética a duração dos relacionamentos, sejam eles como for, não têm importância. O que vale é o estar junto no presente.

5 Para Baudrillard (1993) essa sombra constitui-se da massa que se silencia diante dos acontecimentos e/ou problemas sociais. É difícil até saber suas opiniões. Talvez o ambiente online possa chamar atenção e libertar essa massa desse 
preconceituosos. Diante de tal pressuposto, temos como exemplo estudos relacionados a homoafetividade que resultam da necessidade de se conhecer melhor a construção de identidades sexuais, na tentativa de superação de um discurso relacionado a sexualidade heteronormativa (masculinizada, genitalizada, reprodutiva).

Hall (2001, p. 12) afirma que o sujeito pós-moderno "está se tornando fragmentado, composto não de uma única, mas de várias identidades, algumas vezes contraditórias ou não resolvidas". Os gays, nesse caso, são sujeitos que, vítimas de um modelo imposto por uma sociedade heteronormativa, têm tentado, de uma certa forma, reunir esses fragmentos a procura de um "eu".

Nesse sentido acredita-se que as comunidades online, hospedadas no ORKUT, contribuem para a construção das identidades gays, pois permitem que esses sujeitos, reafirmem sua sexualidade por meio da interação com os outros; ao mesmo tempo em que buscam respostas sobre suas identidades, distorcidas pelos estereótipos criados pela sociedade.

Refletindo sobre o discurso em Foucault (2007), o ORKUT seria um espaço onde certos enunciados podem ser ditos, tentando, de certa forma, "resolver" ou buscar uma autoconstrução do que é ser gay. A análise dessas formações discursivas revelará que a construção de "si”" emana de um conjunto de elementos coexistentes (culturais e/ou sociais) que estão impregnados nos sujeitos desde o nascimento e, a partir da criação de dispositivos, controlam a vida e criam verdades. No entanto, comunidades gays podem ser espaços de resistência, de questionamento e reconstrução conhecimentos.

No caso das comunidades gays, hospedadas pelo ORKUT, são produzidos diversos tópicos que geram discussões/enunciados sobre o que as comunidades e esses sujeitos pensam de 'si' enquanto gays e leva a reflexão sobre as seguintes questões: as comunidades gays seriam espaços de emancipação das identidades ou seriam guetos (espaços de segregação)? Quais as problemáticas mais discutidas e abordadas nessas comunidades? Há um discurso comum? Há um conceito do que é ser gay presente nesses discursos?

Faz-se necessário questionar, também: a interação existente nas comunidades hospedadas no ORKUT possibilitam, a partir dessa nova socialidade, a construção e reafirmação das identidades por

Silêncio neutro, que não é nem alienador e nem libertador. 
meio dos discursos e a compreensão do que é ser gay na atualidade? Os discursos, elaborados pelos gays nas comunidades do ORKUT, são ou não tentativas de superação de uma falsa "anormalidade", conferida àqueles que se declaram gays?

O que pode ocorrer nas comunidades gays do ORKUT é a identificação com o outro, pois os participantes desses espaços buscam se encontrar, se ver, se identificar com aqueles que comungam a mesma condição gay. Então, "a identidade surge não tanto da plenitude da identidade que já está dentro de nós como indivíduos, mas de uma falta de inteireza que é preenchida a partir do nosso exterior" (HALL, 2001, p. 39). Esse exterior pode ser definido como um conjunto de enunciados ditos e não ditos por outros que juntos formam discursos que contribuem para a formação das identidades dos sujeitos em questão.

Assim, optar pelo estudo da construção de identidades gays em comunidades do ORKUT, leva à reflexão sobre o porquê os homossexuais são, há tempos, parte de uma minoria excluída e estigmatizada pela sociedade (ANJOS, 2000, p. 276). Dessa forma, o presente texto evidencia alguns conceitos teóricos que, em conjunto com as análises dos resultados, demonstra que há uma necessidade de que os estudos sobre homossexualidade, homoerotismo e/ou homoafetividade sejam discutidos com mais abrangência; principalmente nas instâncias educacionais e familiares.

Para esse estudo, escolheram-se as comunidades gays hospedadas pelo ORKUT, pois este é a comunidade online mais popular do Brasil, segundo o Ibope NetRantings (2007) ${ }^{6}$, e, também, por ser rica em material, por conter textos, enquetes e fóruns.

Desta forma, definem-se como objetivos específicos: Identificar, a partir da análise do discurso, como são (e se são) construídas as identidades gays nas comunidades hospedadas no ORKUT; Compreender se as comunidades gays se tornaram guetos e/ou espaços de emancipação; Conhecer os conceitos do que é ser gay nos discursos dos participantes; Identificar os assuntos que mais prevalecem nos discursos, promovidos pelas enquetes; Conhecer o que os gays dizem de si nessas comunidades; entender se os discursos gays, presentes nas comunidades, contribuem para a construção de um contra discurso aos discursos presentes na sociedade; Identificar, na construção dos discursos, se existe no espaço online relações de poder que posicionem os discursos de cada

\footnotetext{
${ }^{6}$ Fonte: Marketing e comunidades digitais: do discurso ao diálogo. http://www.ibope.com.br/. Acesso em junho de 2007.
} 
sujeito e conseqüentemente suas identidades.

\section{Teoria Queer e homossexualidade}

As questões sobre homossexualidade tentam ser mais profundamente abordadas nas Teorias Queer. A teórica que mais contribuiu para o desenvolvimento dessa teoria foi Judith Butler; inclusive citada por vários autores.

Em um texto denominado "El Marxismo y lo meramente cultural", Butler (2000) aborda a questão da política queer como um movimento de luta em prol de um reconhecimento cultural. E, com isso, questiona o vínculo que se estabelecia entre parentesco e a reprodução sexual; assim como o vínculo existente entre a reprodução sexual e a sexualidade.

Dessa forma, para Butler (2000) via-se nos estudos queer um importante retorno a crítica marxista da família, baseado em uma perspectiva dinâmica que desenvolvia uma análise socialmente contingente e socialmente transformada do parentesco.

Conseqüentemente, a Teoria Queer emerge, segundo Pino (2007, p. 160), na década de 1980 como uma corrente teórica, em um momento de reavaliação crítica das políticas identitárias. Com relação ao termo queer, deve-se analisar o porque do uso dessa expressão para os estudos homoafetivos. O termo "Queer pode ser traduzido por estranho, talvez ridículo, excêntrico, raro, extraordinário.

Mas, a expressão também se constitui na forma pejorativa com que são designados homens e mulheres homossexuais" (LOURO, 2001, p. 546). A palavra ou termo é usada no sentido de oposição a uma ordem dominante. "A política queer está estreitamente articulada à produção de um grupo de intelectuais que, ao redor dos anos 1990, passa a utilizar este termo para descrever seu trabalho e sua perspectiva teórica" (LOURO, 2001, p. 546).

Essa oposição a um grupo dominante ou sexualidade dominante (hétero) é que contribuirá para a constituição da identidade homossexual, que pode ser pronunciada, principalmente porque há pensadores que defendem sua existência, tendo por base as questões culturais e sociais a ela relacionadas.

A Teoria Queer entra em oposição a uma política binária da existência da heterossexualidade como única forma socialmente autorizada de se relacionar sexualmente. Sendo assim, os estudiosos 
dessa teoria procuram desmistificar e propõem a idéia de que a homossexualidade é uma forma diferente de relacionamento e que deve ser aceita e respeitada como uma outra possibilidade de se viver a sexualidade.

Para se oporem a uma política regulatória, imposta pela heteronormatividade, os teóricos queer baseiam-se em alguns estudos de Foucault, como a história da sexualidade, que dirá que essa concepção normalista de heterossexualidade foi instituída na época vitoriana, século XVIII, como forma de regulação social. Não se podia, como visto em Foucault (1988), se deixar levar pelos prazeres da carne e prejudicar o nascimento do atual sistema vigente (capitalismo).

A Teoria Queer problematiza, a partir de diversos questionamentos, a homossexualidade e discute a identidade sexual, considerando uma diversidade de formas de relacionamentos homoafetivos. Essas características são fundamentais para discussão e para o entendimento dos estudos gays no contexto atual.

Nesse sentido, identifica-se na Teoria Queer, um desejo de poder se expressar e se relacionar a partir de uma outra sexualidade, a homossexual, hoje marginalizada e questionar sexualidades normativas (heterossexualidade). Não que essa teoria se atenha somente à discussão das sexualidades "transgressoras" (PINO, 2007, p. 161), ela procura, também, relacionar sexualidades com outros fatores que influenciam o questionamento das identidades pessoais (raça, religião, classe social dentro outros).

Pino, citando Butler (2007, p. 163) argumenta que o "objetivo em torno dos movimentos em torno do gênero e da sexualidade, como de seus pesquisadores, é questionar o que é humano, quais são os parâmetros usados para compreendê-lo assim o que torna as vidas habitáveis e verdadeiras".

Esses parâmetros pelo que se observa, tanto nos estudos psicanalíticos quanto nas observações antropológicas, são influenciados pelo social. E este, regulado por modelos estratégicos e coercivos por uma classe ou instituição dominante. Dessa forma, é necessário elucidar tais discursos que visam normalizar as práticas sociais na tentativa de (re)construir e instituir um discurso contrário àquele hegemônico. "A tarefa desses movimentos é lutar para refazer a realidade, mudar as normas que regem o humano, negociar o que é habitável ou não" (BUTLER apud PINO, p. 166).

Por fim, vê-se como características principais dessa teoria: subversão contra a heteronormatividade; o questionamento do que é ser humano; questionamento à normatividade; 
oposição a uma concepção binária de sexualidade; desejo a incoerência; assumir a diferença porém não anormalidade; problematização de outros fatores como a raça, classe em relação a sexualidade e a desconstrução e re(construção) de discursos hegemônicos relacionados à normatividade sexual e dual dos gêneros.

O próximo passo será avaliar os discursos dos participantes das comunidades online do ORKUT escolhidas para este estudo, a fim de se testar aplicação (ou não) dessa teoria no contexto social que vivem os gays.

\section{Identidade, homossexualidade e comunidades online}

Há diversos trabalhos científicos que têm analisado as comunidades online na construção das identidades pessoais. Em todos os trabalhos, observa-se que o sujeito nos ambientes online vai em busca de algo que não encontra no mundo off line. Esse mesmo sujeito encontra na rede uma fuga e um porto seguro para se expressar. Logicamente, cada tribo online cria leis, implícitas de regulação dos discursos pois, como se viu em Foucault (2007), nem tudo pode ser dito em qualquer lugar.

As opiniões sobre a Internet variam muito. Em alguns casos são noticiados na televisão ou jornais profissionais de diversas áreas que têm criticado o uso da Internet afirmando que criam-se indivíduos hedonistas e enfermos (viciados em Internet), mas têm-se pesquisas que chegam à conclusão de que a Internet e as comunidades online são novos espaços de relacionamentos que apenas atualizam as antigas formas de estar junto (praças públicas por exemplo).

Apresenta-se aqui alguns resultados de pesquisas anteriores que tratam das comunidades online, de forma menos pessimista e abordam a construção das identidades gays nesses espaços.

Nussbaumer (2004) conclui em sua pesquisa “E-jovens: potencialidades da escrita de si”, que na comunidade online por ela estudada, os adolescentes podem expressar e construir sua homossexualidade pois não são censurados, segundo a autora, como nos ambientes off line. Ela afirma que esses espaços encorajam os adolescentes a assumirem sua homoafetividade fora do mundo online.

Com relação à construção das identidades, Nussbaumer (2004) afirma que os jovens têm, na comunidade E-jovens, a necessidade de se identificar com figuras famosas, que de certa maneira, abonem suas condutas. Não há, no E-jovens, segundo a pesquisadora, um engajamento político em 
defesa ou em prol da questão homossexual e, sim, mais a questão de estar junto e de se relacionar com os outros jovens. Entretanto é interessante ressaltar que eles não se mostram conformados com a realidade heteronormativa.

Por fim, o trabalho de Nussbaumer (2004) chega à conclusão que a escrita de 'si' na comunidade E-Jovens, parte da necessidade dos sujeitos em tornar-se homossexuais e serem reconhecidos como tal porém, que esse reconhecimento seja verdadeiro, sem discriminação e preconceito.

Alonge (2006) em sua pesquisa “A rede e o ser", aponta alguns pressupostos referentes a construção das identidades gays nos espaços virtuais. Na análise do discurso feita por ele em $b \operatorname{logs}$, há uma necessidade dos homossexuais em tornar a homossexualidade conhecida e risível em uma homossexualidade aceita. Isso ocorre, segundo o autor, por meio de uma auto-afirmação e autoaceitação enunciada sempre na rede. Ele afirma, também, que para maioria dos homossexuais, fora dos blogs, a homossexualidade ainda continua indizível.

Para ele, a escrita nos blogs é uma forma de desabafo e compartilhamento de experiências entre os sujeitos. Alonge (2006) completa que, na falta de vínculos familiares consistentes, o círculo de amigos [nos blogs] torna-se o único lugar em que o homossexual 'que tomou uma resolução', pode exprimir suas emoções e seus sentimentos.

Fernandes (2007) no seu estudo "Folkcomunicação e Mídia Digital: a luta simbólica pela cidadania nos espaços de homocultura virtual" afirma que a Internet não apenas insere os sujeitos homossexuais em um espaço em que podem exprimir suas identidades, mas também como trincheiras para o combate ao preconceito. Esses espaços virtuais, segundo o pesquisador, cristalizam as autoidentidades no sentido da reafirmação e reconstrução da homossexualidade.

De uma maneira geral, as pesquisas sobre a homoafetividade nos ambientes online, revela uma necessidade, por parte dos gays, de uma auto-aceitação. Nesse sentido, a convivência com outros, nesses espaços, lhes dão a chance de se conhecer por meio do outro e se fortalecer entendendo que ele, enquanto gay, não está sozinho no mundo.

\section{"Homens que amam homens" e "eu apoio o casamento gay": apontamentos gerais}

Existem, nas comunidades pesquisadas, a presença de três importantes conceitos que foram 
essenciais para as análises feitas. São eles: tribalismo, teoria queer e o amor.

É importante voltar a algumas características sobre o tribalismo, as quais encontram-se bastante presentes e foram fundamentais para o entendimento do processo de sociabilidade, nas comunidades online pesquisadas.

Outro importante fator que merece análise são as contribuições da Teoria Queer para o estabelecimento dos estudos gays. Uma vez que esta teoria ofereceu elementos importantes para a análise dos resultados.

Por fim, "O banquete de Platão", em especial o debate dos filósofos sobre o amor, traz contribuições importantes sobre esse sentimento tanto explorado e declarado pelos participantes das comunidades do ORKUT.

Apresenta-se aqui apontamentos gerais sobre esses conceitos e a ligação destes com as comunidades gays pesquisadas.

\section{Tempo das tribos: tribalismo nas comunidades do orkut}

Michel Maffesoli (2006) demonstra em sua obra "O tempo das tribos: declínio do individualismo nas sociedades de massa" que vivencia-se nessa era pós-moderna o retorno das tribos arcaicas, porém, com algumas características peculiares do tempo atual. Se antes as sociedades tribais prezavam pelo afeto, ética da convivência, compromisso com os integrantes da tribo, proximidade física e duradoura; hoje, as tribos pós-modernas (neotribalismo) prezam pela vontade de estar junto, do gozo, da eterna sensação de bem-estar; pela interação, pelo compartilhamento, porém uma vida instantânea, relações efêmeras, falta de compromisso com os outros, uma ética da estética que preza mais pelo momento do gozo que da duração das relações. Sendo que a estética refere-se ao sentir em comum e a ética uma espécie de laço coletivo (MAFFESOLI, 2006, p. 54).

Essas tribos pós-modernas são formadas, segundo Maffesoli (2006, p. 14) por indivíduos com características, gostos semelhantes. As comunidades gays do ORKUT formam essas tribos em busca de um pertencimento, ou do que o autor chama de "comunidades emocionais" (MAFFESOLI, 2006, p. 40). Nessas comunidades, eles partilham de sentimentos comuns em busca de respostas e compartilhamento de idéias.

Entretanto, é percebido na análise das falas dos participantes das comunidades, que eles 
assumem diferentes "máscaras" na sua convivência off line. Sendo que essas "máscaras" servem de esconderijo e escudo em prol da necessidade de sobrevivência; pois, a sociedade ainda não vê como comum ou normal suas práticas homoafetivas.

Maffesoli (2006, p. 70), tomando por base o mito de Dionísio ${ }^{7}$ da filosofia grega, fala sobre as diversas máscaras assumidas pelos indivíduos. Nesse sentido, segundo ele, o "vitalismo" é a força que impulsiona as variadas transformações, variações, máscaras assumidas pelo sujeito para alimentar a vida. Não existe perfeição pois ela significa morte, existe, sim, um eterna imperfeição como sinal de vida (MAFFESOLI, 2006, p. 78).

Assim, ao assumir diferentes papeis a partir dessas máscaras, o gay se vê inserido em uma socialidade e se torna uma persona que necessita mudar de figurino para assumir seu lugar em seus diferentes ambientes (MAFFESOLI, 2006, p. 133). O caráter aparentemente negativo assumido pela socialidade apenas revela uma (quase) obrigação do sujeito em assumir suas diferentes identidades na sua vida social. Principalmente, porque as mídias existentes potencializam o descobrimento de novos mundos, jeitos e expondo uma gama de identidades pret-à-porter (ROLNIK, 1997).

Ao mesmo tempo, essa socialidade pode, também, potencializar que diferentes identidades se confrontem e, a partir daí, novas identidades surjam. A socialidade se torna superficial porque ela é, por si própria, saturada: de sujeitos, culturas, mundos, idéias, identidades.... A saturação vem ao encontro do vitalismo, entendido como desejo da descoberta do novo, da construção e reconstrução. Por isso, a necessidade de descobrir novas pessoas, novos mundos, culturas, idéias e novas tribos.

\section{As comunidades do orkut e a Teoria Queer}

Foucault (1988) em "História da sexualidade I: a vontade de saber" contribuiu para o estabelecimento da Teoria Queer a partir do questionamento sobre as formas normalizadas de se lidar com o sexo no século XVIII. Apesar de o intuito da obra não pretender erguer uma bandeira em defesa da homossexualidade, mas, sim, refletir sobre a sexualidade de uma maneira geral, seja na heterossexualidade ou na homossexualidade, os estudiosos Queer valeram-se dessa base para questionar os dispositivos que acabam por anormalizar a homoafetividade.

7 Dionísio por ser filho de uma relação ilegítima entre Zeus e Sêmele é perseguido por Hera esposa legítima de Zeus. Para proteger o filho Zeus confere-lhe diversas aparências, metamorfoseando em diversos animais. Dionísio então, usa essas máscara para sobreviver a fúria de Hera. 
Nesse contexto, a Teoria Queer se fez sentir nos discursos dos participantes em diversos pontos. A contribuição mais efetiva dessa teoria para o presente trabalho pode ser destacada, tendo por base os estudos de Silva apud Louro (2004, p. 48): "Pensar Queer significa questionar, problematizar, contestar todas as formas bem-comportadas de conhecimento e de identidade".

Assim, as comunidades estudadas pretendem, também, questionar o que foi e está imposto para a sociedade como normal. Isso corrobora muito bem com os estudos de Derrida apud Louro (2004, p. 42) sobre a operação de desconstrução de certos binarismo que impõem a superioridade de um objeto em relação a outro. Em outras palavras, impõem-se uma certa hierarquia/superioridade na oposição criada entre heterossexualidade/homossexualidade, contribuindo, da mesma forma, para o estabelecimento da Teoria Queer.

Agora, existem alguns pontos dentro da Teoria Queer que parecem não "combinar" com os ideais buscados pelos sujeitos gays. Na definição de Louro (2004, p. 07) "Queer é tudo isso: é estranho, raro, esquisito. Queer é, também, o sujeito da sexualidade desviante. É o excêntrico, que não deseja ser "integrado" e muito menos "tolerado". Isso porque na análise das falas, ao que parece, a maioria quer, sim, ser aceita, quer sim ter o seu direito reconhecido e não quer ser visto como esquisito na sociedade.

Corroborando, igualmente, com a teoria Queer, existem alguns aspectos que fazem com que essa teoria se aproxime do desejo deles: subversão contra a heteronormatividade - a partir da luta em prol do casamento; eles dizem que as uniões estáveis não podem ser exclusivas a heterossexualidade (apesar que, como se verá mais a frente, questiona-se o desejo, aceitação e adequação dos gays ao casamento); o questionamento do que é ser humano - dentro desses aspectos questionam as pesquisas e questionam até mesmo os relacionamentos héteros; oposição a uma concepção binária de sexualidade - apesar de demonstrarem um pouco de confusão eles entendem que a homossexualidade é "fato" e propõem a desconstrução e re(construção) de discursos contrahegemônicos relacionados à normatividade sexual e dual dos gêneros.

A única questão relacionada à Teoria Queer que não foi posta em discussão foi com relação a raça. Aliás, pela análise das variáveis a grande maioria dos participantes das comunidades são brancos. Imagina-se que, questões como, essa deve ser mais abordada na academia e os participantes das comunidades gays; na sua maioria, pelo que se pôde perceber nos perfis, não eram pesquisadores 
interessados temáticas como essa.

\section{O banquete e o discurso sobre o amor}

O amor é enaltecido a todo momento nas falas dos participantes das comunidades. O que é esse amor? O que é amar? A resposta pode estar no "O banquete de Platão". Os filósofos que fazem parte desse banquete procuram cada um exaltar Eros (Deus do amor) e, nessa exaltação, definem, cada um a seu modo, o que é o amor.

Fedro fecha seu discurso dizendo que o "amor é dos deuses o mais antigo, o mais honrado e o mais poderoso para a aquisição da virtude e da felicidade entre os homens, tanto em sua vida como após sua morte”. Na fala dos participantes as palavras virtude e felicidade realmente são sinônimas do que eles imaginam o que é o amor.

Após a fala de Fedro é a vez de Pausâmias discursar sobre o amor. Para esse filósofo o amor não é composto de uma única coisa. $\mathrm{O}$ amor é bem e o mal, belo e vulgar. O primeiro está ligado ao zelo para com o outro e, o segundo, está ligado aos desejos unicamente carnais. Essa dualidade do amor também é encontrada nos discursos dos gays. Eles querem essa completude do amor: unir o desejo sexual a uma cumplicidade mútua.

É a vez de Erixímaco conferir palavras ao amor. O amor para o filósofo é inserido num plano mais ligado a natureza:

ele [o amor] não está apenas nas almas dos homens, e para com os belos jovens, mas também nas outras partes, e para com muitos outros objetos, nos corpos de todos os outros animais, nas plantas da terra e por assim dizer em todos os seres é o que creio ter constatado pela prática da medicina, a nossa arte.

Porém, ele também acredita que o amor tem duas faces: o bem e o mal ou em suas palavras “o sadio e o mórbido". O amor em Erixímaco é, nesse contexto, mais racional e revela que as duas faces do amor formam a harmonia que o corpo necessita. Quando os gays confiam ao amor a plenitude do relacionamento eles buscam esse equilíbrio: a sensualidade do corpo e sublimidade da alma.

Aristófanes, por sua vez, toma o amor como a eterna busca, como um anseio que vai além do corporal. A eterna busca, segundo Aristófanes é o resultado da separação dos corpos antes 
naturalmente andróginos 8 . "É, portanto, ao desejo e procura do todo que se dá o nome de amor". Embora se proclame a fragilidade dos laços humanos, esse sentimento de eterna procura fica bem evidente nas falas dos gays, os quais, mesmo desanimados com relacionamentos efêmeros, sempre comungam com a esperança de encontrar sua alma gêmea.

$\mathrm{O}$ amor para Agatão vai muito além das relações físicas e emocionais entre as pessoas. O amor move o mundo; é compassível; é símbolo de amizade e cumplicidade. Essa pode ser a explicação da relação de respeito e confiança a que muitos gays têm de suas mães. Elas são citadas como um das primeiras pessoas a serem informadas da homoafetividade dos filhos. E eles esperam delas o amor caracterizado por Agatão. "É ele que nos tira o sentimento de estranheza e nos enche de familiaridade, promovendo todas as reuniões deste tipo, para mutuamente nos encontrarmos, tornando-se nosso guia nas festas, nos coros, nos sacrifícios; incutindo brandura e excluindo rudeza; pródigo de bem-querer e incapaz de mal-querer [...]"

Sócrates, último a exaltar Eros, fala que o amor é aquilo que se deseja. E o que se deseja é aquilo de que se é carente. Mesmo tendo um amado e desejar que esse amado continue seu, desejase algo que está no futuro e, portando, ainda não lhe pertence. Os gays possuem esse tal desejo. Desejo de manter o amor do presente e que a intensidade desse amor dure para o futuro. Quando eles refletem sobre questões relacionadas a velhice gay eles se questionam e é claro desejam que o amor também esteja com eles no futuro. Claro que o amor e o desejo em Sócrates, não se refere somente aos relacionamentos amorosos. Mas, todo o tipo de desejo: de riqueza, trabalho, sucesso, amizade, os quais são também almejados por qualquer um.

Enfim, o amor é esse banquete de beleza, esse conjunto de sentimentos e de coisas que vitaliza o sujeito. E não tem diferença se o amor é gay ou hétero. A diferença está na intensidade de cada um em amar independente de opção sexual. É isso que os filósofos tentaram, no seu conjunto, estabelecer o que é o amo.

\section{Resultados da análise das comunidades}

8 Antes haviam três gêneros duplos em si mesmo, ou seja, homem homem, mulher mulher e homem mulher. Zeus então separou os corpos e a partir daí as metades passaram a se procurarem. O andrógino homem mulher explica a existência da heterossexualidade e os outros: homem homem, mulher mulher caracterizam a homossexualidade (O banquete). 
Falar sobre a construção de identidades gays, no contexto atual, não é um exercício fácil. Além de se deparar com todos os instrumentos e situações que alteram constantemente a construção de identidades, ainda tem-se que lidar com o preconceito. Este, mesmo em tempos Pós-Modernos, existe e torna mais confusa o entendimento que o gay tem do seu "eu".

Entretanto, atualmente, é possível desbravar territórios e buscar além muros, outros conhecimentos que podem, de certa maneira, contribuir para o entendimento de "si".

Nas análises das falas dos participantes das comunidades online gays estudadas, ficou claro o conceito de identidade ligado à interação e aos processos de identificação (HALL, 2001). Viu-se que o gay procura sempre na participação com o outro se auto-conhecer e se auto-construir. Nesse sentido, verificou-se que tais comunidades têm um papel social importante por promoverem encontros e confrontos de idéias que aumentam a carga informacional dos sujeitos ampliando seus conceitos ligados à questão da homoafetividade.

Os estudos sobre gênero foram importantes na compreensão dos fatores relacionados a construção de identidades sexuais. Essas reflexões favoreceram e indicaram a existência da Teoria Queer para o aprofundamento das questões relacionadas com a homoafetividade.

Já a fundamentação teórica sobre cibercultura e as comunidades online foram fundamentais; pois para entender a construção das identidades gays, era preciso compreender o funcionamento e a relação dos indivíduos com essa nova rede social.

Em relação às análises feitas às comunidades online hospedadas pelo ORKUT: "Homens que amam homens" e "Eu apoio o casamento gay", verificou-se que os discursos presentes nas falas dos sujeitos gays, são reflexos de um preconceito crônico da sociedade em relação aos relacionamentos homoafetivos. Essa constatação se deve ao fato de que as falas são carregadas das manifestações de preconceitos que fazem parte da vida da grande maioria dos gays participantes dessas comunidades.

Também, é declarado que a família tem um papel muito importante na decisão do gay em se 'assumir' ou não e parte dessa decisão, quando contrária a revelação de 'si' enquanto gay, vem do medo de ser vítima do preconceito da própria família ou essa mesma família ser vítima do preconceito da sociedade.

Nesse contexto, podem ser destacados outros fatores interessantes encontrados nas análises 
feitas às comunidades estudadas como, por exemplo: participação efêmera, uma vez que há uma grande circularidade de pessoas se credenciando e descredenciando da comunidade; por mais que exista muita informação contra o preconceito à homoafetividade, ainda é muito forte, nas falas dos participantes das comunidades online, discursos que reafirmam os velhos preconceitos, fazendo crer que todos os esforços contra o preconceito existente, ainda são insuficientes para sensibilizar a sociedade; fala-se de religião, no entanto, não há entre os gays uma religião predominante, a não ser uma pequena demonstração de interesse pelo espiritismo, motivado certamente pela abertura dessa religião a esse público.

Viu-se que os resultados aqui apresentados corroboraram, em alguns aspectos, com os estudos anteriores sobre a construção das identidades gays em comunidades online, apresentados na revisão de literatura dessa dissertação. Da mesma forma que em Nussbaumer (2004), os gays querem reconhecimento e respeito; alguns querem se identificar com figuras famosas e sentem, no espaço online, uma certa segurança para expressarem sua homossexualidade.

Com relação aos estudos de Alonge (2006), ao que parece, uma grande parte dos gays não podem se expressar no ambiente off-line como se expressam nos ambientes online e há uma falta de confiança na família; no entanto é um espaço de auto-afirmação (mesmo que isso seja possível somente naquele ambiente).

Meu pai ainda não sabe - tem a mente muito fechada pra eu me aproximar e falar. Minha mãe não aceita de jeito nenhum. Estou indo a uma psicóloga por causa disso (ela me obriga). Disse que se não funcionasse eu iria parar na igreja pra tirarem esse demônio de dentro de mim. Quando assumi, me chamou de tudo: doente, demônio, espírito maligno, doido, pirado, ridículo, escroto, bicha, viado e por aí vai... Horas de briga. Senti repulsa quanto a mim mesmo por duas semanas depois disso. Hoje ela não olha pra mim. Não fala comigo. É só uma mulher estranha morando na casa do meu pai. Não a reconheço. É tão desesperador ficar perto dela, a sós... A expressão de nojo dela entrega que ela vai falar algo a respeito a qualquer momento.

Em Fernandes (2007), acrescenta-se que os resultados têm em comum a utilização das comunidades online como trincheiras contra o preconceito e contribuem para reafirmação e construção da homossexualidade.

Algumas questões foram enunciadas na problematização desse estudo em busca do entendimento sobre a construção das identidades gays na atualidade. Assim, chegou-se a uma constatação geral de análise, propondo respostas a essas indagações que, inclusive, comungam com 
outros estudos relacionados a mesma temática como se poderá perceber. As perguntas feitas foram: As comunidades gays do ORKUT são espaços de emancipação das identidades? Quais são as problemáticas mais discutidas? Há um discurso comum? Há um conceito do que é ser gay presente nos discursos? Há construção e reconstrução de identidades? Há um contra-discurso?

Os discursos, realizados pelos gays nas comunidades online, são ou não tentativas de superação de uma falsa "anormalidade" conferida àqueles que se declaram gays? Sim, mas há algumas considerações. Eles desejam o casamento semelhante ao modelo heterossexual. Nas falas, grande parte, acredita que o casamento hétero é um exemplo a ser seguido como pode ser percebido na fala seguinte:

Acho que boa parte dos gays naum serem respeitados e por causa da falta de amor e por achar que tudo e sexo. So pra finalizar queria dizer qeu sinto uma pequena inveja dos heteros por saberem o que querem e ira atraz, fazer loucuras (necessarias), mas uqe no final das contas conseguem ter a sua femea ou seu macho consigo, do seu lado e juntos construirem uma vida a 2 coisa que infelizmente nos falta!!

Querem também, um relacionamento monogâmico e uma parcela pretende ter filhos. Há um certo medo da solidão. E esta solidão é associada ao não casamento. Portanto, a maioria pensa sim em casar-se. Mas, apesar do desejo de serem inseridos nesse modelo, ao mesmo tempo, dizem que o casamento não pode ser exclusividade dos relacionamentos heterossexuais como queria a sociedade vitoriana.

Olha, a questão é que uma cultura marginalizada ainda não está acostumada a vivenciar um relacionamento completo. Só o gueto. E, no gueto, o que rola mais é sexo. Tem muito gay fútil e promíscuo, mas acho que a tedência será mudar isso quando pudermos vivenciar todas as fases públicas e legais de um relacionamento, por isso apoio o casamento gay. Casar está muito difícil, mas não impossível. Não desista.

Poderia-se concluir que o que os leva a desejarem casamentos no mesmo molde dos casamentos héteros é a garantia de direitos civis. Porém, fica claro que o desejo é da vontade de, acima de tudo, poder ter um parceiro fixo a vida toda ou o máximo de tempo possível, ou seja, uma crença de amor eterno. E, no entanto, Bauman (2004) mostra que laços assim estão cada vez mais frágeis. 
Eles constatam que os relacionamentos (especificamente) gays não duram muito. Nesse contexto, eles próprios entendem que o motivo está no fato de serem gays.

me afastei da comunidade GLS e digo mais, muito do preconceito que se tem quanto à opção homosexual, é justamente a fama dos guetos (sem querer dizer que guetos gays são melhores ou piores do que guetos heteros, pois sem dúvida também existem, mas nós estamos matematicamente em desvantagem óbvia e é isso que nos condena à margem da sociedade hoje) e acho mesmo que muito desse comportamento é fruto do próprio preconceito, enfim, é um ciclo vicioso. Resumindo, não nos sobra muitas escolhas quando queremos conhecer outra pessoa além dessas "areas limitadas" vamos dizer assim... a banalização do sexo é uma realidade pan-sexual hoje, só que no nosso caso, já somos uma parcela reduzida da sociedade... se ainda tiver que filtrar... sobra quase nada, e dá no que dá...

Muitos, também, não se assumem para a família por medo de magoá-la. Se eles têm medo de magoar as famílias e até mesmo desacreditam nos próprios relacionamentos é porque assim como a sociedade em geral, eles acreditam ou associam (mesmo não conscientes disso) que ser gay não é normal.

Alguns discursos proferidos por uma parcela dos gays demonstram indícios negativos relacionados a sua homoafetividade. Indícios como estes foram verificados, também, a partir de estudos como de Sá (2006, p. 01). Segundo a pesquisa os próprios homossexuais têm indícios homofóbicos em "sí" próprios influenciados pela família e pelo meio social.

Bom gente, quem me conhece, sabe que eu odeio esses tópicos de relatos pessoais. Mas atualmente, o fato de homossexualismo ser, ou não pecado, tem acabado com a minha cabeça. Eu temo à Deus, mas sinto com se ti vesse que escolher entre a minha vida espiritual e a minha vida pessoal. Seria justo termos que nos condenar à uma vida de frustração e infelicidade, para provar a nossa fidelidade à Deus?

As comunidades online, ao que parece, pretendem ser espaços de emancipação, apesar de existirem ainda os guetos no ambiente offline, onde se refugiam para namorar e/ou conviver com os seus. Assim, a proposta das comunidades gays do ORKUT é a filiação e discussão de temas relacionados à busca, manutenção e entendimento das suas identidades. Nessa busca os grupos se fortalecem até mesmo na convivência em ambientes off line. Esse processo de emancipação faz parte do projeto reflexivo do "ser" (GIDDENS, 2002) e esse projeto é intensificado pelos próprios sujeitos a partir da busca por identificação (HALL, 2001). 
Olha, a questão é que uma cultura marginalizada ainda não está acostumada a vivenciar um relacionamento completo. Só o gueto. E, no gueto, o que rola mais é sexo. Tem muito gay fútil e promíscuo, mas acho que a tedência será mudar isso quando pudermos vivenciar todas as fases públicas e legais de um relacionamento, por isso apoio o casamento gay. Casar está muito difícil, mas não impossível. Não desista.

Mas, ao mesmo tempo, as comunidades também parecem assumir papel de gueto, pois há discursos que, ainda, só podem ser proferidos naquele espaço. Ou seja, pelos discursos, percebe-se que grande parte não se assume enquanto gay para a família e para a sociedade e suas angústias só podem ser divididas dentro dos espaços das comunidades online do ORKUT “onde as pressões são momentaneamente afastadas e, portanto, onde o homossexual tem mais condições de se assumir e de testar uma nova identidade social" (MACRAE, 2005, p. 299).

Em relação à segregação, principalmente pensando nas comunidades que visam a discussão das problemáticas relacionadas à relações homoafetivas, tal como a comunidade "Eu apoio o casamento gay", verificou-se que elas são abertas a heterossexuais. Isto é, não são fechadas somente ao público gay.

No entanto, a participação maciça ainda é de gays por conta do próprio preconceito existente de héteros que se dizem contra o preconceito sexual, porém não se filiam a essas comunidades por medo de que outras pessoas possam duvidar da sua heterossexualidade.

No geral, as comunidades gays são manifestações de variados desejos. Entretanto, nos mil resultados disponibilizados pelo ORKUT quando se buscou pela categoria "Gays, Lésbicas e Bi”, as comunidades que possuem mais membros são as que se propõem a discutir preconceitos e mitos (principalmente que o gay deseja ser mulher); tentam desconstruir estereótipos; buscam relacionamentos duradouros (leia-se que a relação tenha amor). Fica evidente que existem centenas de outras que são ponto de encontro para troca de vídeos pornográficos, encontros e outros tipos de desejos sexuais e outras práticas (fetiches) que tanto a sociedade, como parcela dos gays, chamariam de promiscuidade. Mas, são menores em quantidade de participantes.

O discurso, que é comum nas comunidades, de um modo geral, é a afirmação que ser gay não significa ser promíscuo (curtir só sexo, não ter compromissos) e que há a busca, pelo menos pela maioria, de uniões estáveis, duradouras, fieis e afetivas. 
Busco um amor, que me queira não apenas para sexo, mas, tb, para um passeio pelo calçadão de uma praia, um cinema, admirar o por do sol, para ver um filme pela TV bem abraçadinho, para um bom bate papo, ouvir música juntos, para um colo num momento triste ou refúgio qdo nos estressamos no trabalho. Um amor com quem dividir os bons e os maus momentos da vida, com seus altos e baixos. Um amor que faça carinho e seja atencioso e romântico. Sou fiel, romântico, dedicado qdo estou namorando e prezo sempre um namoro sério. Ficar não me interessa. Não me preenche. Tive alguns namorados. Um não queria compromisso sério. Outro era muito dependente emocionalmente. Outro, queria ser viver às minhas custas. Acredito ainda no amor entre dois homens. Acredito em sentimentos, pois eu os tenho.

Este é o discurso comum; porém, os debates revelam identidades diferenciadas a cada sujeito. Ninguém pensa completamente igual ao outro. Podem concordar em alguns pontos, porém, discordam em outros. São identidades em transformação e o debate com o outro; cada um expondo suas diferenças, contribuem para a eterna construção do "Eu".

Qual é o conceito de gay mais evidente nas comunidades? Sujeito que, assim como qualquer outro, deseja amar e ser amado. Deseja respeito. Deseja que sua identidade seja reconhecida de forma positiva e não negativa (mesmo que, em alguns casos, inconscientemente eles, de certa forma, deixam transparecer em seus discursos, dúvidas sobre sua condição enquanto gay, como normal ou anormal); tentam construir modelos de existência próprios, pois ainda se observa que é presente, nas suas falas, dúvidas imensas sobre "si"; passam a impressão de uma identidade ainda mal resolvida. Se confundem muito nesse mundo que ainda não oferece lugar a eles; são reprimidos na maioria das vezes e não possuem ou não sentem na família apoio para se aceitarem.

Com relação ao contra-discurso, a comunidade "Homens que amam Homens" e seus integrantes ao denominar a comunidade dessa forma, tentam construir um contra-discurso do senso comum que afirma que gays são afeminados e/ou querem ocupar uma posição feminina e/ou adotar uma identidade de gênero feminina. A comunidade e seus participantes afirmam que são homens; com todas as características culturais que denotam masculinidade (roupas, ações, corpos), mas que, no entanto, sentem atração afetiva e sexual por sujeitos do mesmo sexo.

Em um dos tópicos analisados intitulado: "Difícil... Muito difícil: namorar!" eles fazem críticas ao sexo pelo sexo e a promiscuidade. Esse questionamento e crítica feito por eles ao sexo casual, reflete um contra-discurso a sociedade, também presente muitas vezes na mídia, de que gays são promíscuos e só pensam em sexo. 
Outro ponto que denota uma tentativa contracultural é o fato de eles afirmarem sempre sua masculinidade, por meio dos discursos, ou mesmo, nas fotografias que revelam corpos viris, bem característico do imaginário que se tem do universo masculino. Existem os afeminados e os não afeminados; no entanto, ser gay, para eles, não significa a presença da identidade de gênero feminina em suas identidades. E, na maioria das vezes, esses trejeitos, que lembram gestos femininos, não significam um desejo de ser mulher.

Fica bem evidente qual identidade sexual e de gênero adotada pelos gays nessas comunidades. A identidade sexual revela uma atração por parceiros do mesmo sexo biológico. Enquanto que a identidade de gênero dos participantes está mais ligada a masculinidade, pois, eles querem deixar claro sua virilidade e a negação e negam traços de feminilidade em seus corpos e suas subjetividades.

As relações de poder, presentes nas discussões, estão mais ligadas a um discurso dominante, exterior a comunidade online, do que uma relação de poder entre os participantes dos fóruns. Com isso, não se nega, aqui, que não haja relações de poder dentro da comunidade.

Porém, dentro dela, essas relações estão mais ligadas a uma guerra de discursos, no qual cada um, procura da melhor forma possível, compreender o significado da homossexualidade/homoafetividade em suas vidas.

Já as relações externas à comunidade; revelam uma política de resistência (FOUCAULT, 1979, 1982), dos gays que questiona a heterossexualidade como norma e coloca em discurso outras possibilidades de relacionamentos sexuais/afetivos. Nesse contexto, cria-se uma política da identidade das comunidades, a qual pretende combater a manifestação do discurso dominante, preconceituoso, vitoriano e histórico que tem interferido; em muitos casos, nas discussões dos membros das comunidades, a partir dos dispositivos normativos de poder presente na vida em sociedade.

Entretanto, essa política da identidade, conforme pontua Foucault (1982) não tem que partir de uma necessidade de criação de uma cultura própria para os gays. Nas palavras do autor: “eu não estou seguro de que nós devamos criar nossa própria cultura. Nós devemos criar uma cultura. Devemos realizar criações culturais". Os movimentos sociais, dessa forma, completa Foucault, têm um papel muito importante para que as conquistas dos direitos, sejam eles quais forem, continuem 
aumentando.

\section{Conclusão}

Estudos sobre a homoafetividade, dentro da universidade, possuem espaços restritos. Não há grandes aberturas para que se pesquise sobre tal temática. Na maioria dos casos, os estudos são praticados por pesquisadores gays que encontram nesses debates a possibilidade de luta contra o preconceito.

De certa forma, os resultados dessa pesquisa, revelam essa dificuldade de inserção da temática no meio universitário. Tal fato revela que é necessário levar, com mais profundidade, os resultados e discussões sobre os relacionamentos homoafetivos para dentro dos programas de pesquisa e pós-graduação.

É necessário discutir não só a prática dos relacionamentos mas, também, outras temáticas relacionadas a ela: casamento, família e religião.

Percebeu-se que, até no meio gay, existem tabus que impedem a própria aceitação de $s i$ enquanto gay. Sendo assim, vê-se que são necessárias políticas públicas que levem esse tipo de discussão também para as escolas e famílias.

Os gays, ou pelo menos a maioria deles, ainda vivem escondidos em espaços, muitas vezes chamados de guetos, mas que são locais onde possam se revelar e vivenciar suas verdadeiras identidades.

O espaço online é um desses. Lá eles encontram com outros que comungam a mesma condição e trocam idéias em busca de um "eu" ou reconstrução de "si".

Dessa forma, acredita-se que participar de espaços online como esses contribuem para a reflexão dos sujeitos de diferentes movimentos sociais e aproximam pessoas de pensamentos e idéias semelhantes ou propiciam debates dos contrários. Acima de tudo, contribui para que as diferentes idéias sejam colocadas em discussão para que novos horizontes e novas formas de ver o mundo surjam a partir desses encontros, confrontos possibilitando a (re)construção de identidades.

\section{Referências}

ALONGE, Wagner; MARTINS, Isildinha; GOBBI, Maria Cristina. (Org.). A rede e o ser: auto- 
afirmação identitária nos espaços de homocultura virtual. In: FOLKCOM, 9., Anais do UNESCOM. Documento eletrônico. São Bernardo do Campo: UMESP, 2006.

ANJOS, Gabriele dos. Identidade sexual e identidade de gênero: subversões e permanências.

Sociologias, Porto Alegre, v. 2, n. 4, p. 274-305, jul./dez. 2000.

BAUDRILLARD, Jean. A sombra das maiorias silenciosas: o fim do social e o surgimento das massas. 3.ed. São Paulo: Brasiliense, 1993. 86 p.

. Simulacros e simulação . Lisboa: Relógio d'Agua, c1991.

BAUMAN, Zygmund. Amor líquido: sobre a fragilidade dos laços humanos. Rio de Janeiro: Jorge Zahar Editores, 2004.

- Identidade: entrevista a Benedetto Vecchi. Rio de Janeiro: Jorge Zahar Editores, 2005. . Comunidade: a busca por segurança no mundo atual. Rio de Janeiro: Jorge Zahar

Editores, 2003.

Modernidade líquida. Rio de Janeiro: Jorge Zahar, 2001.

BUTLER, Judith. Corpos que pesam: sobre os limites discursivos do "sexo". In: LOURO, Guacira Lopes (Org.). O corpo educado: pedagogias da sexualidade. 2. ed. Belo Horizonte: Autêntica, 2001, p. 151-174.

. El marxismo y lo meramente cultural. A New Left Review, n. 2, p. 109-121 mayo/jun. 2000. Disponível em <http://www.portalcomunicacion.com/cat/aab_txt_det.asp?id_tl_temes=7>. Acceso en: 27 nov. 2008.

Brasileira, 2003.

Problemas de gênero: feminismo e subversão da identidade. Rio de Janeiro: Civilização

FERNANDES, Guilherme Moreira. Folkcomunicação e mídia digital: a luta simbólica pela cidadania nos espaços de homocultura virtual. In: INTERCOM - Sociedade Brasileira de Estudos Interdisciplinares da Comunicação, 7., Anais do Congresso Brasileiro de Ciências da Comunicação da Região Sudeste. Juiz de Fora - MG: [s. n.], 2007.

FOUCAULT, Michel. A arqueologia do saber. 5.ed. Rio de Janeiro: Forense Universitária, 2007.

. A ordem do discurso. 15. ed. São Paulo: Edições Loyola, 2007b.

História da sexualidade 1: a vontade de saber. 15 ed. Rio de Janeiro: Edições Graal, 1988.

História da sexualidade 2: uso dos prazeres. Rio de Janeiro: Edições Graal, 1984.

Microfísica do poder. 17.ed. Organização e tradução de Roberto Machado. Rio de Ja-

neiro: Edições Graal, 1979.

. Os corpos dóceis. In:

Vozes, 1987. cap. 1, parte 3, p. 125-129.

Vigiar e punir: nascimento da prisão.14 ed. Petrópolis:

. Michel Foucault uma entrevista: sexo, poder e política da Identidade. Entrevistadores: B.

Gallagher e A. Wilson. Toronto, 1982. [Traduzida]. Disponível em: <http://www.unb.-

br/fe/tef/filoesco/foucault/sexpodident.html>. Acesso em: jan. 2009.

GIDDENS, Anthony. Modernidade e identidade. Rio de Janeiro: Jorge Zahar Editores, 2002.

HALL, Stuart. Nascimento e morte do sujeito moderno. In:

modernidade.5.ed. Rio de Janeiro: DP\&A, 2001. cap. 2, p. 23-46.

A identidade cultural na pós-

LEMOS, André. Cibercultura: tecnologia e vida social na cultura contemporânea. 2.ed. Porto Alegre: Sulina, 2004.

. Cibersocialidade: tecnologia e vida social na cultura contemporânea. Disponível em: < http://www.facom.ufba.br/ciberpesquisa/txt_and3.htm > . Acesso em: 22 maio 2008. . Arte da vida: diários pessoais e webcams na Internet. In: INTERCOM - Sociedade 
Brasileira de Estudos Interdisciplinares da Comunicação, 25., 1-5 set 2002, Salvador-BA. Anais do Congresso Brasileiro de Ciências da Comunicação. Disponível em:

<http://reposcom.portcom.intercom.org.br/ dspace/handle/1904/18835 >. Acesso em 18 jun. 2008. LEVY, Pierre. Cibercultura. São Paulo: Ed. 34, 1999. (Coleção TRANS).

LOURO, Guacira Lopes. Teoria queer: uma política pós-identitária para a educação. Rev. Estud. Fem., 2001, v. 9, n. 2, p.541-553. ISSN 0104-026X.

2004.

Um corpo estranho: ensaios sobre sexualidade e teoria queer. Belo Horizonte: Autêntica,

MACRAE, Edward. Em defesa do gueto. In: GREEN, James N.; TRINDADE, Ronaldo. Ho-

mossexualismo em São Paulo e outros escritos. São Paulo: Editora UNESP, 2005. cap. 4, p. 291337.

MAFFESOLI, Michel. A terra fértil do cotidiano. Revista Famecos, Porto Alegre, n. 36, ago. 2008.

. O tempo das tribos: o declínio do individualismo nas sociedades de massa. 4. ed. Rio de

Janeiro: Forense Universitária, 2006. (Ensaio \& Teoria).

MANGUEL, Alberto. Uma história da leitura. São Paulo: Cia das letras, 1997

MORIN, Edgar. Introdução ao pensamento complexo. 2.ed. Lisboa: Instituto Piaget, 1990.

(Coleção Epistemologia e Sociedade).

NUSSBAUMER,G.M.. E-jovens: potencialidades da escrita de si. In: CONGRESSO BRASILEIRO

DE CIÊNCIAS DA COMUNICAÇÃO, 27., 2004. Porto Alegre. Anais... São Paulo: Intercom, 2004. CD-ROM.

PERFIL dos internautas. Diário da Manhã, Goiânia, dez. 2006. Disponível em:

<http://www.dm.com. br>. Acesso em 24 dez. 2006.

PINO, Nádia Perez. A teoria queer e os intersex: experiências invisíveis de corpos des-feitos. Cad.

Pagu, jan./june 2007, n.28, p.149-174. ISSN 0104-8333.

PLAT ÃO. O banquete. Disponível em: <http://www.dominiopublico.gov.br>. Acesso em: dez.

2008.

PRIMO, Alex. Perspectivas interacionais de comunicação: alguns antecedentes. In: PRIMO, Alex

(Org.). et al. Comunicação e interações. Porto Alegre: Sulina, 2008, p. 9-15.

ROLNIK, Suely. Toxicômanos de identidade. [1997]. Disponível em:

<http://www.pucsp.br/nucleodesubjetividade/Textos/SUELY/Toxicoidentid.pdf > . Acesso em 20 de março de 2008.

SÁ, Dênia Dória de. Uma visão homossexual da homossexualidade. Cientifico, v. 02, n. 6, 2006. SILVA, Mozart Linhares da. Educação intercultural e pós-modernidade. Revista Mal Estar e Subjetividade, Fortaleza, v. 03, n. 01, p. 151-163, mar. 2003.

SILVA, Sérgio Gomes da. O conflito identitário: sexo e gênero na constituição das identidades.

Revista Brasileira de Sexualidade Humana, São Paulo, v. 10, n. 1, p. 70-85, jan./jun. 1999. 